\title{
TRAJETÓRIAS DE ESTUDANTES DO ENSINO FUNDAMENTAL ANOS FINAIS E O PAPEL DA ESCOLA NA CONSTRUÇÃO DA ESPERANÇA
}

DOI: $10.48075 /$ RI.V24I2.26561

\begin{abstract}
Emiliana Abade ${ }^{1}$
Marcelo Martins Bueno²

RESUMO: Este artigo aborda a esperança em estudantes de escola pública do Ensino Fundamental Anos Finais, caracterizada como sentimento que se firma na realidade vivida, capaz de mover o indivíduo a buscar possibilidades que o levam a lutar para mudar uma situação que incomoda (FREIRE, 2018). Procurou-se investigar se a escola contribui para a manutenção desse sentimento, uma vez que a realidade social dos estudantes apresenta fatores que os levam a experimentar o sentimento inverso. A coleta de dados foi feita mediante a realização de grupos focais que proporcionaram o diálogo entre estudantes que expressaram o sentimento de esperança por meio de crenças, projetos, experiências e relatos. A análise dos dados apontou que a escola representa a base de formação para um futuro sólido, além de lugar de acolhimento que se contrapõe à violência. Entretanto os estudantes revelaram percepção crítica sobre condições culturais que provocam o abandono e mencionaram a bagunça, o vandalismo e as brigas como elementos que descaracterizam a esperança que o espaço escolar deveria promover. Uma observação relevante é a visão que os estudantes têm de uma escola de periferia que se distingue de outras e o modo menos ou mais esperançoso como enfrentam essa percepção. Ao final, apresenta-se a discussão sobre a necessidade de uma educação com vistas à esperança, contrária a uma postura imobilizante dos atores envolvidos no processo ensino-aprendizagem e promotora do diálogo entre professores e alunos que, juntos, analisam a situação real vivida pelos educandos para que, identificados os desafios, busquem soluções para transformá-la.
\end{abstract}

Palavras-chave: Educação; Esperança; Processo ensino-aprendizagem.

\section{TRAJECTORIES OF STUDENTS OF FUNDAMENTAL EDUCATION MIDDLE SCHOOL AND THE ROLE OF SCHOOL IN THE CONSTRUCTION OF HOPE}

\footnotetext{
${ }^{1}$ Mestra em Educação, Arte e História da Cultura pela Universidade Presbiteriana Mackenzie. Possui graduação em Letras - Licenciatura Plena - pela União das Faculdades Barão de Mauá (1996), Especialização em Gestão Escolar (2012) e Violência Doméstica contra Crianças e Adolescentes (2001). E-mail emilianaabade@gmail.com ${ }^{2}$ Doutor e Mestre em Filosofia Política pelo Programa de Pós Graduação em Filosofia da Pontifícia Universidade Católica de São Paulo. Graduado em Filosofia e em Pedagogia. Atualmente é Pró Reitor de Extensão e Cultura e Professor Titular do Corpo Permanente do Programa de Pós Graduação em Educação, Arte e História da Cultura da Universidade Presbiteriana Mackenzie. E-mail marcelo.bueno@mackenzie.br
} 
ABSTRACT: This article addresses the hope in public school students of the Fundamental Education Middle School, characterized as a feeling that is established in the lived reality, able to move the individual to seek possibilities that lead him to fight to change a situation that bothers (FREIRE, 2018). This exposition is an attempt to investigate whether the school contributes to the maintenance of this feeling since the social reality experienced by students constantly presents factors that lead them to experience the opposite feeling. Data collection was carried out within focus groups that provided a dialogue between students who expressed the feeling of hope through beliefs, projects, experiences, and reports of life situations. The analysis of the data was carried out, which showed that the school represents the training base for a solid future, in addition to being a welcoming place that opposes the violence. However, the students revealed a critical perception about cultural conditions that cause abandonment and mentioned the mess, vandalism, and fights within the school as elements that de-characterize the hope that this space should promote. A relevant observation is the students' view of a peripheral school that is distinguished from others and the less or more hopeful way in which they face this perception. Lastly, the discussion on the need for education with a view to hope is presented, contrary to an immobilizing posture of the actors involved in the teaching-learning process and promoting dialogue between teachers and students who, together, analyze the real situation lived by the students so that, once the challenges are identified solutions to transform them.

Key Words: Education; Hope; Teaching-learning process.

\section{INTRODUÇÃO}

É um desafio compreender o que fundamenta a prática docente, já que o próprio professor, em sua trajetória, carrega uma articulação de vozes e saberes que compõem um arcabouço de teorias, práticas vivenciadas e modelos socializados de prática. Nesse conjunto de saberes estão crenças, valores, conhecimento, convicções, experiências, comprometimento e outros fatores que influenciam a ação pedagógica. Considerar os saberes pessoais aliados aos profissionais deixa claro que o exercício da docência não se restringe ao tempo presente e, por esse motivo, é importante conhecer a trajetória do professor que, ao longo da vida, vai constituindo sua identidade profissional inspirada no rigor e na competência técnico-científica cuja tarefa é a busca permanente.

Uma trajetória de aprendizagem tem como elemento essencial a esperança capaz de levar o indivíduo a ter forças para lutar contra a inexorabilidade da vida em que, diariamente, surgem situações que exigem a esperança crítica que move o indivíduo para transformar uma realidade. A ideia inicial deste trabalho surgiu desse sentimento que permeia uma trajetória de vida, pois foi sem renunciar a ele que se empreendeu uma busca inquieta de um fazer no mundo. Causa incômodo ao profissional de educação perceber-se diante de crianças, adolescentes e jovens que parecem prescindir da esperança em suas jornadas, e isso gerou motivação para a realização de uma pesquisa que, entre outras coisas, 
investiga se a escola promove esperança e se contribui para a manutenção desse sentimento.

Uma reflexão sobre a prática docente constata a necessidade de reforçar a capacidade crítica dos educandos assim que se depara com condições desfavoráveis à verdadeira aprendizagem. Nesse sentido, o presente artigo procura trazer elementos que contribuam para uma reflexão crítica sobre uma prática que não reconhece a profissão de ensinar como transferência de conhecimento, mas busca criar possibilidades para sua produção e sua concretização (FREIRE, 2018). Por isso, é preciso deixar claro que o objetivo do estudo é analisar se a esperança pode ser um aspecto importante do processo ensinoaprendizagem e reconhecer, portanto, fatores que impulsionam esse sentimento e outros que o comprometem.

Para a realização da pesquisa foi usada a técnica dos grupos focais que consiste em reuniões com um pequeno número de interlocutores, neste caso, foram realizados dois agrupamentos com seis estudantes cada. A técnica exigiu a presença de um moderador e de um relator: o moderador teve o papel de focalizar o tema, promover a participação de todos, inibir os monopolizadores da palavra e aprofundar a discussão; o relator, além de auxiliar o moderador nos aspectos organizacionais, esteve atento para nada deixar de anotar sobre o processo criativo e interativo, garantindo os registros na íntegra, uma vez que o enfoque da pesquisa encontra-se nos grupos.

Embora se reconheça que a esperança não seja suficiente, ela é necessária para que o indivíduo adquira gosto pela luta permanente, sem fraquejar e sem abrir mão de buscar possibilidades, pois é esse sentimento que leva à ação que resulta transformação. Quando a esperança se vê comprometida, o que comumente ocorre em situações de perdas, solidão, agressão e ausência de diálogo, o indivíduo experimenta o imobilismo que o leva à adaptação, à aceitação do fatalismo de circunstâncias adversas ou ainda a crenças em soluções mágicas que não resultam mudança e, neste contexto, se a educação que deveria representar a abertura de perspectivas não produzir sentido, a realidade tornar-se-á estática e imutável.

De modo geral, os estudos abordam o cotidiano de estudantes e sua relação com a escola, buscando compreender como o sentimento de esperança move-os na busca por possibilidades e na realização de projetos de vida. Também trazem aspectos subjetivos, como, por exemplo, o sentido de esperança e situações que a produzem ou que levam à 
perda desse sentimento e, nessa perspectiva, investiga-se o papel da escola, a fim de compreender se ela proporciona o diálogo que incentiva uma postura crítica e indagadora de seus educandos de modo a desenvolver a esperança indispensável à aprendizagem.

\section{A ESPERANÇA E O PROCESSO ENSINO-APRENDIZAGEM}

O conceito de esperança que embasa este trabalho encontra-se em Pedagogia da esperança: um reencontro com a pedagogia do oprimido, em que Freire (2018) afirma que não compreende o indivíduo que prescinde da esperança para viver, pois sem ela experimenta-se o sentimento inverso, a desesperança. Ocupando o lugar da esperança, uma necessidade ontológica, a desesperança é uma ameaça que pode resultar em trágico desespero e colocar o indivíduo em uma situação em que se vê impossibilitado de agir e de lutar para transformar a realidade.

O autor ressalta a necessidade de educar a esperança, uma vez que esperar somente não é suficiente. Trata-se de uma postura ingênua achar que a esperança por si transforma o mundo, isso não ocorre, mas abrir mão desse sentimento é também perigoso, na medida em que a vida não se pauta exclusivamente em atos calculados, mas está sujeita a imprevisibilidades, barreiras e desafios que precisam ser enfrentados, e a pura espera não vence esses embates. Educar esse sentimento consiste, inicialmente, em mergulhar à procura da razão de ser de uma dor que se sente, mas tomar consciência dessa dor não é ainda resolvê-la, pois que as soluções dependem de ações concretas. Parte-se em busca de possibilidades que devem ser buscadas como realidades a serem concretizadas. Isso que pode ser, mas ainda não é, porque encontra-se no plano da possibilidade, é o "inédito viável".

A expressão "inédito viável" é utilizada na obra de Freire (2018) como categoria que impulsiona a crença no sonho possível, ou seja, a concretização de algo que antes se apresentava inviável, mas que, sendo o homem dotado de imaginação e criatividade, torna concreta a realização desse sonho. Nessa perspectiva, da crença no sonho possível, é que o homem imaginativo e curioso não para de buscar e de aprender. Em processo permanente de busca, os indivíduos vão desvelando as coisas e os fatos, pois é essa leitura de mundo que possibilita a decifração crítica de "situações-limite", que precedem o "inédito-viável". A percepção de uma "situação-limite" dá-se quando, em lugar de aceitarem de modo dócil e 
passivo um condicionamento que se opõe à sua liberdade, os indivíduos vislumbram uma situação desafiadora e dirigem-se à sua superação.

Esta é a razão pela qual não são as "situações-limite", em si mesmas, geradoras de um clima de desesperança, mas a percepção que os homens tenham delas num dado momento histórico, como um freio a eles, como algo que eles não podem ultrapassar. No momento em que a percepção crítica se instaura, na ação mesma, se desenvolve um clima de esperança e confiança que leva os homens a se empenharem na superação das "situações-limite". (FREIRE, 2018, p.126)

Desse modo, a esperança precisa ancorar-se na realidade vivida, uma esperança que deseja e vai à luta do que se quer por direito de todos. Diante de um obstáculo, o indivíduo dá início à ação desafiadora, num clima de esperança e de confiança, na tentativa de solucionar os problemas da sociedade em que vive. Toma distância do problema que incomoda para entendê-lo em sua essência, em profundidade. Percebido e destacado, esse problema precisa ser enfrentado, pois enfrentá-lo faz com que deixe de ser um sonho e passe a se tornar realidade. Para que esse processo ocorra, a educação tem papel fundamental, seja na formulação de bons argumentos para tornar viável o sonho possível, seja para indicar a necessidade do sonho ou da esperança.

Freire (2018) apresenta o diálogo como possibilitador de liberdade, a que leva à crença do sonho possível, sem que se imponha uma leitura de mundo pré-concebida. Para ele, somente a prática dialógica leva o sujeito a refletir e a agir, tomando consciência de que é possível a transformação de si e do meio em que está inserido. O diálogo idealizado implica um profundo amor ao mundo e aos homens, sendo ato de criação, recriação, coragem, compromisso, valentia e liberdade.

Enquanto na teoria da ação antidialógica a conquista, como sua primeira característica, implica um sujeito que, conquistando o outro, o transforma em quase "coisa", na teoria dialógica da ação, os sujeitos se encontram para a transformação do mundo em co-laboração. (FREIRE, 2018, pp.226/227)

Na ausência do diálogo, o mundo mitificado, pré-concebido pela classe dominante não se revela um problema, mas algo dado, como se os indivíduos fossem livres para estudar e trabalhar onde quisessem, para fazerem escolhas, mas a realidade desenha-se de outro 
modo. Para a manutenção de um modelo opressor de relação, no lugar do diálogo ocorrem os comunicados e depósitos de informações que reforçam soluções mágicas e infundadas.

A prática pedagógica pensada neste trabalho não é solitária, mas solidária, ela não se faz apenas com ciência e técnica. Nela, o indivíduo abre-se ao mundo e ao outro num princípio de relação dialógica que se dá na forma de disponibilidade. Essa disponibilidade confirma a curiosidade e a inquietação, própria dos homens, que diminui distâncias. Para encurtar essas distâncias, é preciso usar ferramentas atuais e debater sobre elas e as questões de que tratam, isso caracteriza um ato de querer bem aos educandos porque revela preocupação com as questões que os ocupam, atormentam, e afetividade não se acha excluída do conhecimento. O professor não pode estimular sonhos impossíveis tampouco criar barreiras que impeçam o educando de "Ser Mais" (FREIRE, 2018).

"Ser Mais" diz respeito à humanização que, assim como a esperança, é inclinação natural do ser humano. Quem oprime se desumaniza ao desumanizar o oprimido e, nesse sentido, ambos, opressor e oprimido, estão desumanizados. Ao constatar que os homens pouco sabem sobre si, pois são seres inconclusos, conscientes de sua inconclusão, Freire propõe uma luta pela humanização, pela desalienação. Para humanizarem-se, os indivíduos precisam reconhecer-se como sujeitos do processo histórico, não somente como objetos com direito apenas à sobrevivência, inanimados. Propõe, assim, a investigação do pensar do povo com o povo e, caso se constate que o pensar do povo é mágico ou ingênuo, a superação dessa fraqueza se dará na ação. Para ele, os homens "serão mais" quando, além de pensarem criticamente, atuarem sobre a situação em que se encontram.

Pedagogia do oprimido aponta a importância da conscientização do sujeito que vivencia uma relação de dominação, para uma educação realmente libertadora. Sociedades que se pautam na relação de dominação produzem sujeitos oprimidos com medo de liberdade e sujeitos opressores que se gratificam sob uma falsa generosidade. Para o autor, até mesmo a educação está submetida a relações de poder, uma vez que em sociedades desiguais a pedagogia dominante é a das classes dominantes. Freire critica a concepção bancária de educação por entender que ela reproduz a dinâmica da dominação. Nela, o educador deposita o conhecimento no aluno, e este é meramente ouvinte, objeto estático, manipulável e adaptável à situação imposta.

Para o pensador, só existe saber na invenção, na busca inquieta e, nesse processo, o conhecimento é contínuo e progressivo, porque a aprendizagem só ocorre a partir da Ideação. Revista do Centro de Educação, Letras e Saúde. v. 23, n², 2021. e-ISSN: 1982-3010. 
reflexão. Ela não é neutra nem apolítica, mas a construção da própria esperança. O povo participa ativamente como sujeito desse processo cultural, de educação, e sua ação e reflexão são capazes de transformar o mundo. O educador, por meio do diálogo problematizante e participante, procura capacitar seus educandos para a transformação da consciência ingênua em consciência crítica da realidade. Saber pouco de si justifica a opção dos indivíduos por assumirem atitudes fatalistas, religiosas, mágicas ou místicas, ao invés de consciência crítica.

Quando uma situação é vista como imutável, a tendência dos indivíduos é adotar uma postura fatalista e sem esperança. Essa postura fatalista acaba buscando fora da própria realidade a explicação para a impossibilidade de atuar. Nesse sentido, a crença mágica leva o indivíduo a defender-se de incertezas para fortalecer a confiança, para reduzir a ansiedade e para encontrar válvulas de escape em situações aparentemente sem saída. A mudança de uma percepção mágica, distorcida da realidade, para uma percepção crítica da mesma não é tarefa fácil, ela ocorre na problematização de uma realidade concreta, implica um novo enfrentamento do indivíduo com sua realidade, em que se reconhece sujeito que deve atuar para transformar e não se adaptar a essa realidade desumanizante.

O educando se reconhece conhecendo os objetos, descobrindo que é capaz de conhecer, assistindo à imersão dos significados em cujo processo se vai tornando também significador crítico. Mais do que ser educando por causa de uma razão qualquer, o educando precisa tornar-se educando assumindo-se como sujeito cognoscente e não como incidência do discurso do educador. (FREIRE, 2018, p.65)

A proposta pedagógica de Freire exige um exercício de disciplina intelectual do educando que necessita vir sendo forjada desde a infância, na Educação Infantil. Para ele, não se ensina a aprender, mas a prática cognoscente leva os educandos a irem se tornando sujeitos cada vez mais críticos. Neste tempo altamente tecnologizado, Freire (2018) propõe a superação da curiosidade ingênua, associada ao saber do senso comum, à curiosidade epistemológica, pois esta aproxima-se de forma cada vez mais metodicamente rigorosa do objeto cognoscível. Não se trata de uma ruptura do perfil ingênuo para o indagador, mas um exercício de desenvolvimento da curiosidade crítica com a qual é possível defender-se de excessos advindos da expansão da tecnologia, em que os indivíduos acrescentam algo do que fazem a algo que o mundo impôs. Desse modo, a ciência e a tecnologia colocam-se a 
serviço da humanização dos indivíduos, sem que sejam antagônicas à formação humanista proposta pelo educador.

Uma sociedade que de fato se preocupa com a educação, pois esta é fenômeno dinâmico e permanente, bem como é a vida, precisa recuperar a prática do diálogo proposto por Freire (2018). Essa abordagem de ensino enfatiza o sujeito como principal elaborador do próprio conhecimento, considera, portanto, as relações interpessoais, as emoções e a personalidade em seu processo. O princípio de uma escola humanista é a autonomia democrática; nela, estabelece-se o clima de aprendizagem, compromisso e liberdade para aprender. Sua teoria fundamenta-se nos princípios da valorização da cultura do outro, do ouvir o outro, da certeza da incompletude do ser humano, da conscientização, da democracia e, sobretudo, do diálogo.

\section{A ESCOLA}

A instituição escolar onde estudam os alunos que participaram da pesquisa está localizada no Jardim Parque Morumbi na Zona Sul da cidade de São Paulo, entre a comunidade de Paraisópolis e a Avenida Giovanni Gronchi, importante avenida do bairro Morumbi, a um quarteirão de cada um desses pontos de referência. $O$ prédio apresenta piso térreo e dois andares, no térreo estão o pátio, quadra coberta, salas de direção, vicedireção, professores, secretaria, biblioteca, cozinha, cantina, depósito de materiais e banheiros. Há oito salas de aulas em cada um dos andares superiores, e a escola recebe estudantes do Ensino Fundamental Anos Finais no período diurno, sendo 6ㅇ e 7으 ano, no período da manhã, 8 e 9o ano, no período da tarde, e Ensino Médio, no período noturno, o que significa um total de, aproximadamente, mil e oitocentos estudantes nos três períodos.

A escola oferece merenda aos educandos, no entanto, não há refeitório. Crianças, adolescentes e jovens alimentam-se no pátio, em pé ou sentados no chão, pratos e talheres são de plástico para evitar acidentes. Não há tampouco anfiteatro ou auditório, as apresentações organizadas por professores e alunos, bem como reuniões de pais que envolvem toda a comunidade escolar, ocorrem no pátio ou na quadra e, geralmente, todos permanecem em pé. As salas de aula contam com o quadro verde, escrito a giz, carteiras, mesa e cadeira do professor, cortinas e ventilador. Nos corredores, há somente prateleiras que comportam livros didáticos e cartazes de trabalhos feitos por alunos são expostos nas Ideação. Revista do Centro de Educação, Letras e Saúde. v. 23, n², 2021. e-ISSN: 1982-3010. 
paredes dos dois andares. Esses andares são acessados por escadas, não há rampas, portanto, pessoas com deficiência ou mobilidade reduzida não conseguem dirigir-se de forma autônoma para as salas de aula.

Nessa descrição do espaço escolar, observa-se a falta de atenção a pormenores de um espaço que deve ser pensado, construído e mantido para um contexto em que se requer o exercício da curiosidade epistemológica (FREIRE, 2013). É oferecendo um ambiente realmente limpo, decorado, silencioso, com materiais didáticos que possam ser usados e consultados por professores e alunos que a escola deixa claro que aquele espaço deve ser respeitado e, por consequência, a direção, funcionários e professores podem cobrar esse respeito por parte dos alunos. Esse descuido acentua-se na medida em que se toma conhecimento de que algumas salas de aula apresentam goteiras e, quando chove, professores, alunos e funcionários previnem alagamentos usando baldes e revezando-se para passar panos a fim de evitar que se formem poças.

A comunidade de Paraisópolis ocupa a área de um quilômetro quadrado com população de oitenta a cem mil habitantes e cerca de doze mil desses habitantes são analfabetos. A construção das moradias ou barracos é feita de forma desordenada e sem planejamento. Segundo o último censo, realizado em 2010, Paraisópolis é a oitava maior favela do Brasil e chama atenção pelo contraste, literalmente muro a muro com o bairro do Morumbi. Calcula-se que $80 \%$ da população local seja de origem nordestina, porque a região foi, e continua sendo, um grande espaço de acolhimento de migrantes daquela região. Inicialmente, eles vieram para São Paulo, a fim de trabalhar na construção civil. Projetos sociais são desenvolvidos dentro da comunidade para dar suporte à educação, no entanto, a população convive com a poluição sonora do baile funk, a prostituição, a violência, o tráfico de drogas e a miséria (FÓRUM MULTIENTIDADES DE PARAISÓPOLIS, 2012?).

Os estudantes são de famílias de baixa renda, baixa escolaridade e poucos pais e/ou responsáveis têm emprego fixo. A violência é um fator presente na vida da maioria deles, que ocorre no seio da família, na comunidade, além de ser decorrente de privações, por exemplo, de saneamento básico e lazer. A escola se esforça para transformar algumas situações, mas nem sempre consegue uma solução diante das dificuldades vividas pelos alunos e suas famílias, o que comumente dificulta a aprendizagem e o pleno desenvolvimento. Nesse sentido, observa-se que a escola distancia-se de sua função primordial para focar na atenuação de problemas sociais. 
É claro que o enfrentamento e a superação dessa violência não podem ser ignorados, e implicam o posicionamento de todos os atores da escola, além do poder público. Diretores, professores, funcionários, alunos e seus responsáveis, bem como parcerias com Unidades Básicas de Saúde que atendem a comunidade têm papel na discussão crítica e na proposição de melhores condições para facilitar o processo ensino-aprendizagem desta escola, em um cenário em que não se deseja que a violência seja aceita como valor, ainda que ela seja legítima. A comunidade escolar tem concentrado esforços para o enfrentamento da violência, por entender que o oposto dela não é apenas a 'não-violência', mas a inclusão na cidadania e sua vivência plena.

Em uma comunidade como Paraisópolis, a escola representa espaço de integração social, mais do que de aprendizagem de conhecimentos científicos. Nesse sentido, os alunos que a frequentam tornam-se vítimas de uma dinâmica que o mercado impôs: "escola como centro de acolhimento social para os pobres, com forte retórica na cidadania, e escola do conhecimento e da aprendizagem para os ricos" (LIBÂNEO, 2016, p.54). O objetivo amplo do mercado, em nível internacional, é conter a pobreza, uma vez que educação e desenvolvimento econômico caminham paralelamente. De acordo com essa lógica, a escola privilegia conhecimentos práticos que visam à empregabilidade precária para os que vão viver somente do trabalho.

No entanto, essa mesma escola está inserida na dinâmica de ter os resultados educacionais ranqueados por meio de avaliações externas. É importante deixar claro que a decisão de se implementar uma avaliação de desempenho é sempre externa à escola, e escolas estaduais, como esta em que se realizou a pesquisa, participam de avaliações em nível estadual e nacional, SARESP (Sistema de Avaliação do Rendimento Escolar do Estado de São Paulo) e Prova Brasil, que geram os índices: IDESP (Índice de Desenvolvimento da Educação do Estado de São Paulo) e IDEB (Índice de Desenvolvimento da Educação Básica). Os resultados dessas avaliações são dados públicos e o fato de serem apresentados na forma de ranking, muitas vezes, impulsionam a comunidade escolar para o próprio desmonte, uma vez que a aprendizagem de seus estudantes é comparada com aquela que ocorre em contextos completamente diversos.

De acordo com Young (2007), as escolas tornaram-se vítimas das necessidades da economia, e a educação, portanto, transformou-se em um mercado na competição por alunos e fundos. Com a valorização do conhecimento voltada para resultados e metas, o 
processo de aprendizagem em si tornou-se desgastante e entediante para professores e alunos, redundando em absenteísmo de professores, mudanças constantes na gestão escolar, ausência de clareza dos objetivos da escola, metodologias repetitivas e oferta de conteúdos que pouco sentido fazem aos educandos. Nessa perspectiva, a dinâmica expressa o desfiguramento da escola que, por consequência de políticas a que está submetida, acaba ela própria desvalorizando a formação cultural e científica.

Nesse novo paradigma de escola para pobres, de acordo com uma visão economicista, a educação é entendida como necessidade natural que responde a leis de sobrevivência e que deve, em consequência, ser satisfeita como a fome e a moradia. Assim, "o direito ao conhecimento e à aprendizagem é substituído pelas aprendizagens mínimas para a sobrevivência" (LIBÂNEO, 2012, p.23). Na medida em que aumentam os índices de escolaridade, representados pela universalização do acesso e permanência, tornam mais graves as desigualdades sociais de acesso ao saber. Com isso, à tão sonhada escolarização de base, incentivada por pais de estudantes cujo acesso lhes foi restrito, segue um fracasso representado por iletrismos, abandonos e repetências.

Trata-se de uma política aparentemente humanista, uma vez que tem como princípio a convivência dos alunos e a experiência da sociabilidade, porém esse novo padrão carece de conteúdo e o próprio acolhimento e socialização são deficientes, num ambiente em que o número de profissionais é insuficiente e os professores são mal remunerados. A noção aparentemente ampliada do papel do ensino resulta a impossibilidade de desenvolvimento pleno dos estudantes, visto que as escolas orientam-se pelo princípio de necessidades mínimas de aprendizagens. É importante que uma escola como esta em que se realizou a pesquisa cumpra algumas funções sociais e assistenciais, tendo em vista o contexto em que atua, mas sem que essas funções confundam-se com o objetivo principal que é a formação cultural e científica de seus educandos.

Uma mudança na escola diz respeito também a uma mudança na formação de professores para que se sintam fortalecidos para atuar no contexto que se apresenta. Mudanças essas que não podem ser pautadas pelas lógicas de mercado e de desintegração de instituições, mas pela construção da profissionalidade docente que não só prepara de forma técnica, científica e pedagógica, mas incluem a responsabilidade de dimensão coletiva da profissão de professor. Ademais, a prática educativa é afetividade, alegria e esperança, esta "tem uma tal importância em nossa existência, individual e social, que não devemos 
experimentá-la de forma errada, deixando que ela resvale para a desesperança e o desespero" (Freire, 2018, p15).

\section{ESPERANÇA, DIALOGICIDADE E CONFIANÇA}

Para o desenvolvimento do trabalho, optou-se pela técnica do grupo focal por perceber-se que os estudantes, independentemente da faixa etária, tinham a vivência com o tema da esperança, de tal modo que podiam trazer experiências cotidianas para a discussão. Formaram-se dois grupos: um de seis alunos do 6으 ano e outro de seis alunos do 9o ano do Ensino Fundamental Anos Finais, a fim de observar peculiaridades de perfis desses dois anos escolares. A escolha dos participantes ocorreu de modo aleatório, sendo alguns por indicação de professores, outros pela casualidade de um encontro pelos corredores da escola, de modo a garantir que a busca não incorresse na seleção de perfis semelhantes nem de proximidade afetiva com a pesquisadora tampouco de grupos de amigos da mesma turma.

Buscou-se compreender ideias e sentimentos, bem como fatores que influenciam motivações ou falta de motivação em determinados posicionamentos. O papel do moderador foi essencial no sentido de criar uma atmosfera permissiva, confortável em que todos sentiram-se à vontade para expor pontos de vista. O moderador não apresentou posicionamento, proporcionando uma troca efetiva entre os participantes sobre o tema em discussão. Durante a prática, surgiram situações inesperadas, como: choros, silêncios prolongados e expressões monossilábicas quase inaudíveis. Em tais situações, buscou-se despertar confiança e gerar empatia, para conduzir o grupo em direção aos objetivos da pesquisa. A interação entre os participantes foi elemento diferencial porque resultou em respostas do grupo acerca do tema, que levaram a conclusões que dizem respeito a questões coletivas.

Participaram dos grupos focais doze estudantes que atendiam aos critérios de inclusão definidos para esta pesquisa, isto é, estudantes de 6ㅇ e 9o ano da mesma escola pública estadual, situada na Zona Sul da cidade de São Paulo, e moradores da comunidade de Paraisópolis. Durante a trajetória escolar, os estudantes, em sua maioria, frequentaram a escola pública estadual ou municipal. O primeiro grupo focal contou com a participação de 
seis estudantes do 6ㅇ ano do Ensino Fundamental Anos Finais, sendo três do sexo feminino e três do sexo masculino. A idade dos participantes variou entre doze e catorze anos. $\mathrm{O}$ segundo grupo focal contou com a participação de seis estudantes do 9o ano do Ensino Fundamental Anos Finais, sendo três do sexo feminino e três do sexo masculino. A idade dos participantes variou entre catorze e dezessete anos.

\section{IDAS E VINDAS DE UMA ESPERANÇA INDISPENSÁVEL}

Nesta seção, apresenta-se a análise acerca dos dados coletados, articulando-os com achados presentes na literatura científica, com ênfase ao papel da escola na manutenção da esperança, aspectos que levam à preservação desse sentimento e outros que o colocam em risco, bem como perspectivas sociais e educacionais relacionadas aos projetos de estudantes, nesta etapa escolar. A reflexão crítica sobre a prática docente, o diálogo com os estudantes e os estudos consultados possibilitaram a realização de um trabalho que identifica idas e vindas que melhor viabilizam a razão de ser da esperança, pois esta não se encontra na descoberta, não se traduz na certeza do achado, mas movimenta a busca (FREIRE, 2013), entendida como imprescindível para a aprendizagem.

Os participantes afirmaram o que pensam sobre a esperança e, ao definirem esse sentimento, destacaram-se três aspectos relevantes: primeiramente, para alguns, o sentido de esperança revela ingenuidade, porque é desprovida de ação, por ela compreendem-se pensamentos positivos e mágicos capazes de transformar uma realidade; o segundo foi que alguns estudantes relacionaram a esperança à ideia de conquista, o que para Freire (2018) consiste em uma ação antidialógica, já que implica uma dinâmica entre sujeito e objeto em que este é conquistado por aquele. De acordo com a visão desse autor, a conquista concebe um mundo mitificado, pois o que não se pode conseguir é transformado pela classe dominante em recurso para a admiração do povo que se mantém alienado.

Um exemplo de mito em que os estudantes demonstraram acreditar é o de que são livres para trabalhar onde quiserem, sem considerar o mundo como problema, mas como algo dado e que eles devem ajustar-se às dinâmicas de poder que esse mundo que conhecem impõe. O terceiro aspecto revela a esperança firmada na prática, portanto, suscetível à educação, em que o indivíduo reconhece a importância desse sentimento que o 
move a buscar possibilidades e a lutar para transformar a realidade. $\mathrm{O}$ desejo de mudança da realidade é expresso quando os estudantes afirmam que querem ajudar os pais, pois demonstram consciência crítica de uma situação de injustiça que os incomoda e, reconhecendo-se sujeitos, podem tornar-se capazes de intervir.

De modo geral, a escola é vista pelos estudantes como espaço que promove esperança, uma vez que é a base de formação para um futuro sólido e, nessa perspectiva, ouvem-se vozes de familiares internalizadas de quem não teve acesso ou não pôde concluir a Educação Básica e, portanto, reconhece-se a manifestação do desejo de que para os filhos a vida pode ser diferente, já que o acesso à escola lhes está assegurado. Os participantes apresentaram uma percepção crítica sobre condições culturais que provocam o abandono escolar, como: a necessidade do ingresso no mercado de trabalho e a gravidez precoce; apontaram ainda que há quem se desvie do caminho para estar na rua exposto à violência, espaço que caracterizam como oposto à escola acolhedora e integradora.

Entretanto, há estudantes que se incomodam com a bagunça, a sujeira, o vandalismo e as brigas dentro do espaço escolar, fatores que descaracterizam a esperança que esse espaço poderia promover. Cabe aqui considerar que o desrespeito com o espaço compromete a ação pedagógica, pois somente a oferta de um ambiente cuidado deixa claro que deva ser preservado e, por consequência, seja possível cobrar respeito por parte dos alunos. Embora a escola apresente o enfrentamento e a superação da violência como questões que exigem atenção, e iniciativas vêm ocorrendo para que ela não seja aceita como atitude natural, ela está presente no ambiente e, por colocar em risco a esperança, também prejudica o processo ensino-aprendizagem.

Outro ponto relevante é a visão que se tem de uma escola de periferia que se distingue de outras. A interpretação aproxima-se do estudo sobre o dualismo de uma escola do conhecimento para ricos e uma escola de acolhimento social para pobres (LIBÂNEO, 2012). Diante dessa visão, há alunos que percebem o problema e reconhecem a possibilidade de mudança deste espaço por direito de todos, revelando uma postura esperançosa de como fazer concreto o inédito viável, pois, para eles, é difícil transformar uma realidade, mas não é impossível. Todavia, há indivíduos que identificam o problema, mas não empreendem uma luta para a mudança e, com essa postura, abrem mão de defender-se de uma violência a que estão submetidos para adaptar-se a ela. 
Em oposição à ação antidialógica representada pela conquista, alguns estudantes relataram projetos de vida em que a transformação do mundo se dá pela colaboração. Nessa perspectiva, revelou-se o quanto a fome e a miséria alheias causam incômodo, além da violência das ruas observada na própria comunidade. Indignados com essas situações, os estudantes encontram-se diante de desafios em que planejam intervir para superar a dor do outro que é, dessa forma, também deles. Essa postura humanista que recusa o fatalismo de situações perversas leva à busca do "ser mais" (FREIRE, 2018) que não se realiza no isolamento, mas na solidariedade.

Ao solicitar que os estudantes apresentassem seus projetos, buscou-se compreender desejos, expectativas e objetivos, bem como fatores que evidenciassem a esperança ou a falta dela em determinados posicionamentos, além de aspectos sociais e históricos inerentes às trajetórias dos estudantes em suas singularidades, tendo em vista relacioná-los ao processo de construção do conhecimento. Por sua vez, alguns estudantes deixaram transparecer indefinições que podem ser associadas ao momento de crise de sentidos que se vive atualmente, marcada pela falta de crença na mudança, além de ocasionar uma reflexão sobre a função da escola em articular conhecimentos com atitudes e valores, a fim de colaborar na organização reflexiva de pensamentos.

Do conjunto dos depoimentos, depreende-se que o estudo não foi citado como parte de uma ação ou etapa para a concretização dos projetos dos estudantes do Grupo 1. Diante disso, pode-se concluir que falta a esses estudantes a disciplina necessária do ato de estudar, de aprender e de conhecer, e essa vem sendo encarada como puro entretenimento ou pode ser que o que a escola ensina não é apreendido pelos estudantes na sua razão de ser. Os interesses e os saberes dos educandos, construídos na prática comunitária, e o ensino do conteúdo escolar parecem não ter relação e, nesse sentido, a escola pode estar falhando por deixar de discutir com os estudantes a realidade concreta que se deva associar com a disciplina cujo conteúdo se ensina na escola.

Diferentemente do Grupo 1, os estudantes do segundo grupo apontaram a escola e os estudos como ação ou, ao menos, etapa dessa ação na busca pela concretização de seus projetos. Diante disso, pode-se concluir que os educandos passam a apreender, ao longo do percurso do Ensino Fundamental Anos Finais, um valor que diz respeito à razão de ser dos saberes ensinados na escola que se relaciona com o projeto que buscam realizar. Contrariamente a isso, pode-se depreender que a educação que esses estudantes vêm 
recebendo não esteja estimulando a opção de mudança da realidade e eles mostram-se inclinados à adaptação, portanto, a não transformação da realidade. A curiosidade ingênua acerca do que buscam para si, representada em algumas falas pelo fato de a simples permanência na escola contribuir para a concretização de um projeto, não transita para a inquietação indagadora própria daqueles que se aproximam com rigor do objeto cognoscível.

Projetos e sonhos confundem-se durante os depoimentos porque os estudantes deixam transparecer que não creem em sua realização. De acordo com a teoria que embasa este trabalho, ter sonho se faz uma necessidade, mas é fundamental buscar a razão das coisas para que se evite uma posição defensiva perante incertezas. Traçar rumos e metas é tão importante quanto a esperança de produzir um projeto, a falta de um ou outro representa ameaça da perda da esperança. Um dos estudantes apontou a leitura como fundamental para a construção do conhecimento e, por consequência, para a concretização de seu projeto de tornar-se professor, pois, para ele, a prática leva à organização das ideias e ao aprimoramento da escrita. Entretanto, outras falas revelaram certa simplicidade na interpretação de problemas, o que mostra curiosidade ingênua que precisa ainda transitar para uma inquietação indagadora.

Estimulados a narrar situações da vida em que perceberam a presença ou a perda da esperança, observou-se que a grande maioria relatou uma história sobre a perda desse sentimento. A morte de familiares ou amigos próximos e uma situação em que a ideia de morte esteve muito próxima foram os temas recorrentes para caracterizar a desesperança. Isso se justifica porque experimentar a solidão é uma forma de ausentar-se do mundo, uma vez que estar no mundo implica, necessariamente, estar com o mundo e com os outros para poder transformá-lo (FREIRE, 2015). Por consequência, desintegrar-se desse mundo, sem poder intervir nele, resulta a perda da esperança, como a morte é uma realidade dada, impassível de solução, o indivíduo é forçado a uma adaptação.

O analfabetismo foi apontado como causador de desesperança para três estudantes, ainda que eles estivessem nos Anos Iniciais do Ensino Fundamental quando perceberam essa dor, não saber ler e escrever representou, para eles, motivo de grande preocupação. Nesses relatos, sobressai o procedimento do professor que comprometeu a aprendizagem do aluno quando o menosprezou, decretando que ele era incompetente perante a turma, faltandoIhe o respeito devido. Ensinar não permite subestimar o saber ingênuo que o educando traz 
consigo para a escola, mas trabalhar de modo a ser superado pelo saber produzido pelo exercício da curiosidade epistemológica (FREIRE, 2018).

\section{CONCLUSÃO}

Em síntese, observa-se que a esperança tem tal importância na vida dos indivíduos que acontecimentos que a comprometem levam ao imobilismo. Nesse sentido, estudantes precisam vencer atitudes fatalistas que levam à adaptação para reconhecerem-se sujeitos que pensam e repensam o processo de construção da própria história e, com esperança, denunciam condições intoleráveis para inserirem-se em uma busca permanente que lhes permita fazer e refazer essa história, assumindo-se como sujeitos capazes de transformar. 0 que não pode ocorrer é desistir de procurar a razão de ser das coisas, existir sem questionar sobre o futuro, entender o mundo como se ele estivesse pronto e assim devesse ser aceito.

Compreende-se, pois, que a escola promove a esperança porque é o espaço que propicia condições para o desenvolvimento cognitivo e afetivo dos estudantes os quais contam com a efetiva aprendizagem para a garantia de um futuro melhor. Se a vida já apresenta uma série de condições adversas à manutenção da esperança, a escola não pode representar o espaço que compromete a luta desses educandos por uma realidade melhor. Contudo, a denúncia sobre o desrespeito a esse espaço requer a atenção do poder público e dos gestores escolares, a fim de que garantias mínimas que dizem respeito a uma escola pensada como espaço bem-cuidado de convivência e aprendizagem seja oferecido e, por consequência, possa-se cobrar esse cuidado recíproco de seus alunos.

Uma educação com vistas à esperança promove o diálogo entre educadores e educandos que, juntos, analisam a realidade social em que estão inseridos e, identificados problemas, buscam soluções possíveis para transformá-la. Nesse sentido, os conhecimentos e experiências trabalhados na escola possibilitam que o estudante compreenda as relações do mundo com projetos que objetiva desenvolver. Trata-se de uma abordagem educacional que se revela contrária a uma postura imobilizante dos atores envolvidos no processo ensino-aprendizagem, pois caracteriza-se pela busca permanente pelo conhecimento em que o educando, movido pela esperança, assume-se como sujeito cognoscente cuja 
percepção ingênua da realidade passa à percepção crítica e leva-o a intervir no mundo em uma luta constante, nunca solitária, mas solidária.

\section{REFERÊNCIAS}

BAUMAN, Z. MAURO, E. Babel: entre a incerteza e a esperança. Tradução Renato Aguiar. Rio de Janeiro: Zahar, 2016.

BERGER, P.L. LUCKMANN, T. Modernidade, pluralismo e crise de sentido: a orientação do homem moderno. Tradução Edgar Orth. Petrópolis: Vozes, 2012.

BRASIL. Lei no 9.394, de 20 de dezembro de 1996. Estabelece as diretrizes e bases da educação nacional. Diário Oficial da República Federativa do Brasil. Brasília, DF, 20 dez. 1996. Disponível em: http://www.planalto.gov.br/ccivil 03/leis/19394.htm . Acesso em: 05 jul. 2020.

CALVINO, I. Por que ler os clássicos. Tradução Nilson Moulin. São Paulo: Companhia da Letras, 1993.

DESLANDES, S.F. GOMES, R. MINAYO, M.C.S. Pesquisa Social. Teoria, método e criatividade. Petrópolis: Vozes, 2015.

FÓRUM MULTIENTIDADES DE PARAISÓPOLIS. Paraisópolis. São Paulo: 2012? Disponível em: http://paraisopolis.org/multientidades-de-paraisopolis/paraisopolis/. Acesso em: 05 jul. 2020.

FREIRE, P. FREIRE, A.M.A. À sombra desta mangueira. Rio de Janeiro: Paz e Terra, 2013.

FREIRE, P. Educação e mudança. São Paulo: Paz e Terra, 2014.

FREIRE, P. Pedagogia da autonomia: saberes necessários à prática educativa. Rio de Janeiro: Paz e Terra, 2018.

FREIRE, P. Pedagogia da esperança: um reencontro com a pedagogia do oprimido. São Paulo/ Rio de Janeiro: Paz e Terra, 2018.

FREIRE, P. Pedagogia do oprimido. Rio de Janeiro/ São Paulo: Paz e Terra, 2018.

FREIRE, P. Educação como prática da liberdade. São Paulo: Paz e Terra, 2019.

GADOTTI, M. Boniteza de um sonho: ensinar-e-aprender com sentido. Novo Hamburgo: Feevale, 2003.

GADOTTI, M. Concepção dialética da educação: um estudo introdutório. São Paulo: Cortez, 2003. 
GATTI, B.A. Grupo focal na pesquisa em Ciências Sociais e Humanas. Brasília: Liber Livro, 2005.

GÓMEZ, A.I.P. Educação na era digital: a escola educativa. Tradução de Marisa Guedes. Porto Alegre: Penso, 2015.

HADDAD, S. O educador: um perfil de Paulo Freire. São Paulo: Todavia, 2019.

LIBÂNEO, J.C. Sistema de ensino, escola, sala de aula: onde se produz a qualidade das aprendizagens? Políticas de currículo em múltiplos contextos. São Paulo: Cortez Editora, 2006.

LIBÂNEO, J.C. O dualismo perverso da escola pública brasileira: escola do conhecimento para os ricos, escola do acolhimento social para pobres. Educação e pesquisa, v. 38 n. 1, 2012. p.13-28.

LIBÂNEO, J.C. Políticas educacionais no Brasil: desfiguramento da escola e do conhecimento escolar. Cadernos de Pesquisa, v.46, n.159, jan/mar 2016. p.38-62.

MACHADO, C. Avaliação externa e gestão escolar: reflexões sobre o uso dos resultados. Revista@mbienteeducação, vol. 5, n.1, 2012. Disponível em: http://publicacoes.unicid.edu.br/index.php/ambienteeducacao/article/view/117 Acesso em: 05 jul. 2020.

MAFRA, J.F. PEREIRA, R.A. Educação: a importância do ato de reler. Curitiba: CRV, 2019.

MINISTÉRIO DA EDUCAÇÃO. Base Nacional Comum Curricular. Brasília, 2018. Disponível em: http://basenacionalcomum.mec.gov.br/images/BNCC EI EF 110518 versaofinal site.pdf Acesso em: 05 julho 2020.

MIZUKAMI, M.G.N. Ensino: as abordagens do processo. São Paulo: LTC/EPU, 2013.

MORIN, E. 1921. Os sete saberes necessários à educação do futuro. Tradução Catarina Eleonora F. da Silva e Jeanne Sawaya. São Paulo: Cortez; Brasília, DF: UNESCO, 2000.

NOVOA, A. Firmar a posição como professor, afirmar a profissão docente. Cadernos de Pesquisa, vol.47, n.166, 2017. p.1106-1133. ISSN 0100-1574. Disponível em: http://dx.doi.org/10.1590/198053144843. Acesso em: 14 dez. 2019

ORTIZ, R. Cultura brasileira e identidade nacional. São Paulo: Brasiliense, 2006.

Recebido em 14 de dezembro de 2020.

Aprovado em 19 de janeiro de 2021.

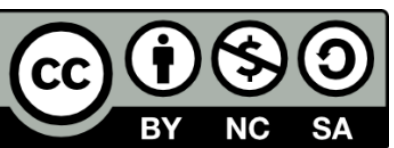

